\title{
artigo
}

\section{Imprinting cultural e aleitamento materno: determinantes e desafios}

\author{
Cultural imprinting and breast feeding: determinants and challenges \\ La impronta cultural y la lactancia materna: determinantes y desafíos
}

\begin{abstract}
RESUMO
Objetivo: investigar a influência do imprinting cultural no aleitamento materno e seus determinantes. Método: revisão integrativa, realizada em novembro de 2020, nas bases de dados que integram a Biblioteca Virtual em Saúde e Cinahl Information Systems, utilizando os descritores indexados Amamentação, Cultura e Determinantes Sociais da Saúde, associado ao operador booleano AND. Resultado: a cultura familiar que permeia o universo da puérpera tende a refletir na decisão em iniciar, continuar e cessar o aleitamento materno, sendo necessário as equipes de saúde se aterem a estes hábitos culturais para que a intervenção aconteça de modo mais direcionado e efetivo. Apresentou relação com a continuação da amamentação quando ocorre os processos migratórios, cujas mudanças culturais refletem na condução desta prática. Conclusão: o impriting cultural atua na prática do aleitamento materno, tanto de modo positivo, quanto negativo, cabendo as ações incidirem nos quesitos que venham a dificultar sua implementação.
\end{abstract}

DESCRITORES: Aleitamento Materno; Tabu Alimentar; Puerpério; Crenças.

\section{ABSTRACT}

Objective: to investigate the influence of cultural imprinting on breastfeeding and its determinants. Method: an integrative review, carried out in November 2020, in the databases that integrate the Virtual Health Library and Cinahl Information Systems, using the indexed descriptors Breastfeeding, Culture and Social Determinants of Health, associated with the Boolean operator AND. Result: the family culture that permeates the universe of the puerperal woman tends to reflect on the decision to initiate, continue and stop breastfeeding, and it is necessary for the health teams to stick to these cultural habits so that the intervention happens in a more targeted and effective way. It was related to the continuation of breastfeeding when migratory processes occur, whose cultural changes are reflected in the conduct of this practice. Conclusion: cultural impriting acts in the practice of breastfeeding, both in a positive and a negative way, and the actions should focus on the issues that may hinder its implementation.

DESCRIPTORS: Breast Feeding; Food Taboo; Postpartum Period; Culture.

\section{RESUMEN}

Objetivo: investigar la influencia de la impronta cultural en la lactancia materna y sus determinantes. Método: revisión integradora, realizada en noviembre de 2020, en las bases de datos que integran la Biblioteca Virtual en Salud y los Sistemas de Información Cinahl, utilizando los descriptores indexados Lactancia Materna, Cultura y Determinantes Sociales de la Salud, asociados al operador booleano AND. Resultado: la cultura familiar que impregna el universo de la puérpera tiende a reflexionar sobre la decisión de iniciar, continuar y dejar de amamantar, siendo necesario que los equipos de salud se apeguen a estos hábitos culturales para que la intervención suceda de manera más focalizada y efectiva. Se relacionó con la continuación de la lactancia materna cuando ocurren procesos migratorios, cuyos cambios culturales se reflejan en la conducción de esta práctica. Conclusión: la impronta cultural actúa en la práctica de la lactancia materna, tanto de manera positiva como negativa, y las acciones deben enfocarse en los temas que puedan dificultar su implementación.

DESCRIPTORES: Lactancia Materna; Tabú Alimentario; Periodo Posparto; Cultura.

RECEBIDO EM: 15/02/2021 APROVADO EM: 02/03/2021

\section{Maísa de Lima Claro}

Mestre em Ciências e Saúde pela Universidade Federal do Piauí - Pl, Secretaria Municipal de Saúde de São João do Piauí, São João do Piauí, PI, BR.

ORCID: 0000000189865753 


\section{Roseanne de Sousa Nobre}

Mestre em Ciências e Saúde pela Universidade Federal do Piauí - PI, Instituto Federal de Alagoas, Maceió, AL, BR. ORCID: 0000-0002-7489-4401

\section{Artemízia Francisca de Sousa}

Doutora em Ciências pela Faculdade de Saúde Pública da Universidade de São Paulo - SP, Universidade Federal do Piauí, Picos, PI, BR. ORCID: 0000-0003-2175-7195

\section{Luísa Helena de Oliveira Lima}

Doutora em Enfermagem pela Universidade Federal do Ceará - CE, Universidade Federal do Piauí, Picos, PI, BR. ORCID: 0000-0002-1890-859X

\section{INTRODUÇÃOO}

0 papel da cultura e dos mitos pode interferir tanto positivamente como negativamente na instituição dos hábitos. Sabe-se que o homem desde o seu nascimento não se conhece apenas por si, mas também pela sua família, tribo, cultura e sociedade. Desta forma, a partir da sua infância ou até mesmo ainda no ventre, o indivíduo já vem estabelecendo relações culturais, e estas passam a ser interiorizadas pelo sujeito criando raízes muito fortes, que Edgar Morin chama de imprinting cultural. ${ }^{(1)}$

O termo supracitado diz respeito à força normalizadora da sociedade, a soma dos conceitos herdados e praticados cegamente, buscando uma performance que se afaste de qualquer possível desvio da norma. Ele pressupõe um padrão de conduta, que pode ser aplicado a todos os aspectos de uma sociedade: o sistema de normas econômicas, sociais, culturais, de comportamento, do uso da língua, dentre outros. O mesmo torna o indivíduo moldado sob semelhança cultural tornando-se assim, produto e produtor de conhecimento/cultura. ${ }^{(2)}$

Partindo da premissa de que os hábitos adquiridos no meio social podem influenciar as decisões e ações futuras, entende-se que a determinação dos mesmos tem deliberação social e, consequentemente, cultural, à exemplo do que tem sido verificado na cultura do aleitamento materno. Entende-se que a cultura pode influenciar o desmame precoce, e observa-se o aumento dessas taxas ainda nos primeiros meses de vida. ${ }^{(3)}$

Assim, ao conceituar a amamentação, precisamos entender que além de um ato biológico, ela é também sócio cultural- mente construída e determinada, sendo um processo complexo com frequente sobreposição das ideologias e valores culturais sobre os aspectos fisiológicos. ${ }^{(4)}$

Dessa forma, o impriting cultural acaba tendo uma duplicidade de funções, onde pode contribuir na formação do conhecimento acerca dos benefícios da amamentação, porém a sua perpetuação de hábitos equivocados na sociedade tem uma carga histórica mawis consolidada, que na maioria das vezes tende a refletir negativamente, como tem indicado a literatura no tocante à prática da amamentação. ${ }^{(5)}$

Por isso, que em virtude da natureza multifatorial dos determinantes do impriting cultural sobre o aleitamento materno, bem como a característica de alteração contínua nos hábitos culturais de uma sociedade ao longo do tempo, objetivou-se, com esse trabalho, investigar a influência do imprinting cultural no aleitamento materno, buscando responder a seguinte questão: como o imprinting cultural atua na prática do aleitamento materno?

\section{MÉTODO}

Trata-se de uma revisão sistemática do tipo integrativa da literatura científica. Esse tipo de estudo inclui a análise de pesquisas relevantes que dão suporte à tomada de decisão e melhoria da prática clínica, possibilitando a síntese do estado do conhecimento de um determinado assunto, além de apontar lacunas que precisam ser preenchidas. Por meio dele, pode-se realizar a síntese de múltiplos estudos publicados e possibilitar conclusões gerais a respeito de uma particular área de estudo. ${ }^{(6)}$

Tendo em vista a quantidade crescente e a complexidade com as quais as informações na área da saúde se apresentam torna-se imprescindível o desenvolvimento de maneiras capazes de delimitar etapas metodológicas e de proporcionar aos profissionais uma melhor utilização das evidências científicas encontradas através de pesquisas desenvolvidas. ${ }^{(7)}$

Para realizar o levantamento de dados do referido estudo foi utilizado o checklist dos Principais Itens para Relatar Revisões Sistemáticas e Meta-análises (PRISMA), disponível na rede Equator. Assim sendo, elaborou-se como questão norteadora para a busca de evidências na literatura científica a seguinte pergunta-problema: como o imprinting cultural atua na prática do aleitamento materno?

O estudo foi realizado através de busca de artigos nas seguintes bases eletrônicas: Literatura Latino-Americano e do Caribe de Informações em Ciências da Saúde (LILACS), Medical Literature Analysis and Retrieval System Online (Medline), Base de Dados de Enfermagem (BDENF) e Scientific Electronic Library Online (SciELO) indexadas na Biblioteca Virtual em Saúde (BVS), bem como na base de dados da Cinahl Information Systems.

Após a definição da questão de pesquisa foram utilizados os descritores de terminologia em saúde extraídos em modo controlado dos Descritores em Ciências da Saúde (DeCS) e Medical Subject Headings (MESH). A busca foi realizada utilizando os descritores em português, associando-os ao conectivo booleano and. Durante a busca, adotaram-se os seguintes cruzamentos dos descritores: Amamentação AND Cultura; e Amamentação AND Determinantes Sociais da Saúde. 


\section{artigo}

Claro, M.L.; Nobre, R.S.; Sousa, A.F.; Lima, L.H.O.

Imprinting cultural e aleitamento materno: determinantes e desafios

A coleta de dados aconteceu de forma independente, sendo adotados como critérios de elegibilidade para a seleção dos artigos: estudos publicados nos últimos cinco anos (2015-2020), textos disponíveis na íntegra, podendo está nos idiomas português, inglês e/ou espanhol, encontrarem-se no formato de artigo, onde destes foram desconsiderados trabalhos de revisões de qualquer categoria, bem como relatos de experiência. Em seguida, foi analisado a adequação do texto de acordo com a questão norteadora, cuja identificação se deu por meio da leitura do título e do resumo e, posterior, leitura do trabalho na íntegra, bem como averiguação sobre a existência de estudos duplicados. Cada estudo selecionado recebeu um código com sequência alfanumérica, no intuito de facilitar a identificação dos mesmos.
Para a seleção dos artigos que atenderam aos critérios de inclusão foi utilizado um quadro sinóptico contemplando o título do manuscrito selecionado, além do país que foi realizado o estudo e o ano de publicação, qual o tipo de estudo, os objetivos, destaque e limitações de cada trabalho, de forma a possibilitar o desenvolvimento de futuras pesquisas na área em questão.

O período de escolha foi definido com o intuito de reunir o maior número de artigos atuais, sendo que a busca de artigos ocorreu por meio de acesso online na Biblioteca Virtual de Saúde (BVS) e na Cinahl Information Systems, no mês de novembro de 2020, e seguiu o fluxo exposto na Figura 1.

Mediante o levantamento das publicações, e aplicação dos critérios de elegibili-

Figura 1 - Seleção dos estudos da revisão integrativa.

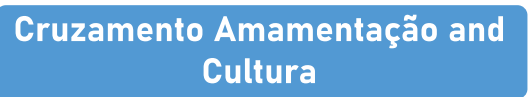

\begin{tabular}{c} 
Busca BVS \\
1743 artigos \\
\hline
\end{tabular}

Idioma: 1689
Últimos 5
anos: 398
Completos: 370
Tipo de
estudo: 161
Análise título: 18
Duplicados: 0
Análise
Resumo: 8

Busca CINAHL 9 artigos

Idioma: 9
Últimos 5
anos: 6
Completos: 2
Tipo de
estudo: 2
Análise título: 1
Duplicados: 0
Análise
Resumo: 0

Total de Publicações: 16 artigos
Cruzamento Amamentação and Determinantes Sociais da Saúde

\section{Busca BVS 83 artigos}

Idioma: 81

Últimos 5 anos: 15

Completos: 12

Tipo de

estudo: 7

Análise título: 2

Duplicados: 0

Análise

Resumo: 2
Busca CINAHL 243 artigos

Idioma: 243
Últimos 5
anos: 171
Completos: 44
Tipo de
estudo: 38
Análise título: 20
Duplicados: 16
Análise
Resumo: 6

Fonte: Elaboração Própria. dade como descritos na Figura 1, pode-se notar que utilizando o cruzamento Amamentação AND Cultura selecionou-se 8 estudos e ao realizar a busca com o cruzamento Amamentação AND Determinantes Sociais da Saúde teve-se 8 artigos, totalizando 16 publicações para leitura e análise na íntegra. Vale ressaltar que após a união das duas bases de dados levantadas, não houve nenhuma duplicação de trabalhos.

\section{RESULTADOS}

Os artigos selecionados para inclusão na amostra foram 16 , sendo a maioria em língua inglesa (oito), publicados no ano de 2016 (cinco), metade publicados em revistas brasileiras (oito). A base de dados que abrigou mais artigos foi a BVS (dez artigos). Na maioria dos estudos, utilizou-se método qualitativo (onze). A análise dos resultados foi realizada de forma descritiva sendo elaborada uma síntese dos estudos, conforme o quadro 1 .

Os principais achados demonstraram que a prática do aleitamento materno é influenciada por vários fatores como mitos ou crenças, dentre elas de que o leite é fraco ou insuficiente para suprir as necessidades do bebê, além de ter sido identificado o descarte do colostro em regiôes da Etiópia por não acreditarem no seu valor nutricional para a nutrição infantil. (3,12,18-19,20-22) $^{2}$

Verificou-se ainda que a cultura de maneira geral tem influência tanto negativa ou positiva, desde o início, manutenção, duração, cessação ou abandono da amamentação, principalmente, em primíparas e mães adolescentes, sendo assim as experiências passadas de geração a geração podem influenciar essa prática, tendo as avós

Quadro 1- Descrição dos estudos por Título, País, Ano, Base, Revista, Método, Principais achados e limitações. Picos,

PI, Brasil, 2020.

\begin{tabular}{|c|c|c|c|c|}
\hline TíTULO & $\begin{array}{c}\text { PAÍS/ANO/ } \\
\text { BASE/REVISTA/ } \\
\text { MÉTODO }\end{array}$ & OBJETIVO DO ESTUDO & PRINCIPAIS ACHADOS & LIMITAÇÕES \\
\hline $\begin{array}{c}\text { Determinants of Weaning } \\
\text { Practices Among Mothers } \\
\text { of Infants Aged Below } \\
12 \text { Months in Masvingo, } \\
\text { Zimbabwe }\end{array}$ & $\begin{array}{c}\text { Zimbabwe /2016 } \\
\text { BVS Annals of } \\
\text { Global Health } \\
\text { Quantitativo }\end{array}$ & $\begin{array}{c}\text { Determinar os fatores } \\
\text { relacionados ao desma- } \\
\text { me de bebês menores } \\
\text { de } 12 \text { meses. }\end{array}$ & $\begin{array}{c}\text { Culturalmente entendem } \\
\text { que o leite materno sozinho } \\
\text { não é suficiente para suprir } \\
\text { as necessidades do bebê. }\end{array}$ & $\begin{array}{c}\text { O estudo realizado somente } \\
\text { na área urbana. }\end{array}$ \\
\hline
\end{tabular}




\begin{tabular}{|c|c|c|c|c|}
\hline $\begin{array}{l}\text { Representaciones } \\
\text { Sociales Frente a la } \\
\text { Lactancia Materna } \\
\text { en Mujeres Rurales } \\
\text { y Urbanas de Jalisco, } \\
\text { México: Estudio } \\
\text { Cualitativo(8) }\end{array}$ & $\begin{array}{l}\text { México/2019 } \\
\text { BVS Revista } \\
\text { Colombiana } \\
\text { de Obstetricia } \\
\text { y Ginecología } \\
\text { Qualitativo }\end{array}$ & $\begin{array}{l}\text { Compreender os } \\
\text { fatores que afetam } \\
\text { negativamente a } \\
\text { amamentação em } \\
\text { mulheres de contextos } \\
\text { rurais e urbanos. }\end{array}$ & $\begin{array}{l}\text { As representações } \\
\text { sociais ou culturais das } \\
\text { mulheres determinam } \\
\text { o início, manutenção } \\
\text { cessação ou abandono da } \\
\text { amamentação. }\end{array}$ & $\begin{array}{l}\text { A investigação restringiu-se } \\
\text { as mulheres beneficiadas } \\
\text { de um programa social } \\
\text { de apenas um Centro de } \\
\text { Jurisdição Sanitária. }\end{array}$ \\
\hline $\begin{array}{l}\text { Factors influencing the } \\
\text { practice of exclusive bre- } \\
\text { astfeeding among nursing } \\
\text { mothers in a peri-urban } \\
\text { district of Ghana }{ }^{(9)}\end{array}$ & $\begin{array}{c}\text { Gana/2017 BVS } \\
\text { BMC Res Notes } \\
\text { Quantitativo }\end{array}$ & $\begin{array}{l}\text { Identificar os fatores } \\
\text { que influenciam a prá- } \\
\text { tica de amamentação } \\
\text { exclusiva. }\end{array}$ & $\begin{array}{l}\text { As mães não declararam } \\
\text { quaisquer práticas culturais } \\
\text { claras que influenciam nega- } \\
\text { tivamente a prática do alei- } \\
\text { tamento, porém relataram a } \\
\text { falta de apoio de cônjuges e } \\
\text { familiares na prática. }\end{array}$ & $\begin{array}{c}\text { A não inclusão dos maridos } \\
\text { para entender o motivo do } \\
\text { não apoio as decisões de } \\
\text { suas esposas na instituição } \\
\text { da amamentação exclusiva } \\
\text { ou não. }\end{array}$ \\
\hline $\begin{array}{l}\text { Significados e experiên- } \\
\text { cias culturais em ama- } \\
\text { mentação entre mulheres } \\
\text { de dois países }{ }^{(10)}\end{array}$ & $\begin{array}{c}\text { Brasil e Fran- } \\
\text { ça/2019 BVS } \\
\text { Rev enferm UERJ } \\
\text { Qualitativo }\end{array}$ & $\begin{array}{l}\text { Identificar as experiên- } \\
\text { cias culturais rela- } \\
\text { cionadas às decisões } \\
\text { maternas para a } \\
\text { amamentação entre } \\
\text { dois países. }\end{array}$ & $\begin{array}{l}\text { Os valores culturais têm } \\
\text { influência no modo como as } \\
\text { mulheres se adaptam à ma- } \\
\text { ternidade. Brasil: valorizaçãã } \\
\text { da amamentação e orien- } \\
\text { tação profissional; França: } \\
\text { acontece o inverso. }\end{array}$ & $\begin{array}{l}\text { A reduzida amostra impede a } \\
\text { generalização dos achados. }\end{array}$ \\
\hline $\begin{array}{l}\text { Motivações para o pro- } \\
\text { longamento da amamen- } \\
\text { tação } 0^{(11)}\end{array}$ & $\begin{array}{l}\text { Chile/2020 BVS } \\
\text { Acta. Paul. En- } \\
\text { ferm. Qualitativo }\end{array}$ & $\begin{array}{l}\text { Explicar a estrutura } \\
\text { motivacional e a decisão } \\
\text { das mães que ama- } \\
\text { mentam por mais de } \\
\text { dois anos. }\end{array}$ & $\begin{array}{l}\text { Para as mães, a infância é o } \\
\text { período motivacional por ex- } \\
\text { celência para integrar a ama- } \\
\text { mentação. Na idade adulta, a } \\
\text { motivação transcendente se } \\
\text { consolida no primeiro estágio } \\
\text { da educação dos filhos e } \\
\text { proporciona a motivação } \\
\text { para o prolongamento do } \\
\text { aleitamento materno. }\end{array}$ & $\begin{array}{l}\text { O número de participantes, } \\
\text { dada a dificuldade de encon- } \\
\text { trar mães que amamentam } \\
\text { além de dois anos. }\end{array}$ \\
\hline $\begin{array}{l}\text { Pre-lacteal feeding practi- } \\
\text { ce and associated factors } \\
\text { among mothers having } \\
\text { children less than two ye- } \\
\text { ars of age in Aksum town, } \\
\text { Tigray, Ethiopia, 2017: a } \\
\text { cross-sectional Studyy }\end{array}$ & $\begin{array}{l}\text { Etiópia/2018 } \\
\text { BVS BMC Pedia- } \\
\text { trics Quantitativo }\end{array}$ & $\begin{array}{c}\text { Avaliar a prática de } \\
\text { alimentação pré-láctea } \\
\text { e fatores associados } \\
\text { entre mães com filhos } \\
\text { menores de } 2 \text { anos de } \\
\text { idade. }\end{array}$ & $\begin{array}{l}\text { Acredita-se que a alimen- } \\
\text { tação pré-láctea tem mais } \\
\text { vantagens que o oferecimen- } \\
\text { to de colostro e o descarte } \\
\text { do mesmo se constitui como } \\
\text { uma prática cultural comum } \\
\text { na regiẫo. }\end{array}$ & $\begin{array}{l}\text { As informações obtidas das } \\
\text { mães podem ter sido sujeitas } \\
\text { a viés de memória e desenho } \\
\text { do estudo transversal. }\end{array}$ \\
\hline $\begin{array}{c}\text { Socio-demographic Fac- } \\
\text { tors Affecting Initiation } \\
\text { and Duration of Breastfe- } \\
\text { eding in a Culturally Diver- } \\
\text { se Area of North Eastern } \\
\text { Greece }{ }^{(13)}\end{array}$ & $\begin{array}{c}\text { Grécia/2019 } \\
\text { BVS Folia Medica } \\
\text { Quantitativo }\end{array}$ & $\begin{array}{l}\text { Registrar as caracterís- } \\
\text { ticas da amamentação } \\
\text { e explorar possíveis } \\
\text { associações com } \\
\text { fatores socioculturais e } \\
\text { demográfico. }\end{array}$ & $\begin{array}{l}\text { Diferentes fatores culturais } \\
\text { estão associados ao início da } \\
\text { amamentação, bem como a } \\
\text { sua duração. }\end{array}$ & $\begin{array}{l}\text { Estudo de design retrospec- } \\
\text { tivo, tornando-o vulnerável a } \\
\text { viés de memória, além disso, } \\
\text { dados sobre paridade e ama- } \\
\text { mentação características dos } \\
\text { irmãos não foram incluídas. }\end{array}$ \\
\hline $\begin{array}{c}\text { Breastfeeding beliefs } \\
\text { and practices of African } \\
\text { women Living in Brisbane } \\
\text { and Perth, Australia }{ }^{(14)}\end{array}$ & $\begin{array}{c}\text { Austrália/2015 } \\
\text { BVS Maternal } \\
\text { and Child Nutri- } \\
\text { tion Qualitativo }\end{array}$ & $\begin{array}{l}\text { Explorar a experiência } \\
\text { de amamentação entre } \\
\text { mulheres refugiadas. }\end{array}$ & $\begin{array}{l}\text { Mudar para um novo país } \\
\text { altera efetivamente o espaço } \\
\text { social retirando as mulheres } \\
\text { das estruturas de apoio e } \\
\text { normas culturais favoráveis a } \\
\text { amamentação,influenciando } \\
\text { a percepção de que a ama- } \\
\text { mentação é considerado um } \\
\text { ato culturalmente vergonho- } \\
\text { so na Austrália. }\end{array}$ & $\begin{array}{l}\text { Diferentes metodologias } \\
\text { utilizadas na coleta de dados } \\
\text { e mulheres na configuração } \\
\text { do grupo. }\end{array}$ \\
\hline
\end{tabular}




\section{artigo}

Claro, M.L.; Nobre, R.S.; Sousa, A.F.; Lima, L.H.O.;

Imprinting cultural e aleitamento materno: determinantes e desafios

\begin{tabular}{|c|c|c|c|c|}
\hline $\begin{array}{l}\text { Interfaces of the discon- } \\
\text { tinuation of breastfee- } \\
\text { ding }^{(15)}\end{array}$ & $\begin{array}{c}\text { Brasil/2016 BVS } \\
\text { Acta Scientiarum } \\
\text { Qualitativo }\end{array}$ & $\begin{array}{l}\text { Identificar condições } \\
\text { para a suspensão do } \\
\text { aleitamento materno } \\
\text { exclusivo. }\end{array}$ & $\begin{array}{l}\text { O conhecimento cultural é } \\
\text { transmitido de geração em } \\
\text { geraçãa, existindo uma forte } \\
\text { relação entre choro, fome ou } \\
\text { necessidade de suplementa- } \\
\text { ção alimentar. }\end{array}$ & $\begin{array}{l}\text { Corte transversal do estudo } \\
\text { e número reduzido de parti- } \\
\text { cipantes. }\end{array}$ \\
\hline $\begin{array}{l}\text { Experiências migratórias } \\
\text { e intergeracionais sobre a } \\
\text { amamentação no espaço } \\
\text { familiar: um estudo de } \\
\text { representações sociais }{ }^{(16)}\end{array}$ & $\begin{array}{c}\text { Brasil/2018 } \\
\text { BVS AQUICHAN } \\
\text { Qualitativo }\end{array}$ & $\begin{array}{l}\text { Analisar as experiências } \\
\text { intergeracionais de } \\
\text { mulheres migrantes da } \\
\text { mesma familia sobre a } \\
\text { amamentação; apreen- } \\
\text { der as representações } \\
\text { sociais dessa população } \\
\text { ao longo das geraçôes } \\
\text { sobre a experiência de } \\
\text { amamentar. }\end{array}$ & $\begin{array}{l}\text { Constata-se que a diversida- } \\
\text { de sociocultural e o território } \\
\text { influenciam grande parte } \\
\text { das mulheres migrantes que } \\
\text { amamentam, tornando-se } \\
\text { necessário compreender } \\
\text { os determinantes regionais } \\
\text { e culturais, e as influências } \\
\text { familiares e geracionais que } \\
\text { permeiam esse processo. }\end{array}$ & $\begin{array}{c}\text { Escassez de estudos } \\
\text { nacionais e internacionais } \\
\text { sobre o tema com enfoque } \\
\text { na intergeracionalidade e } \\
\text { migração, viés de memória e } \\
\text { corte transversal. }\end{array}$ \\
\hline $\begin{array}{c}\text { O processo da amamen- } \\
\text { tação na adolescência: } \\
\text { vivências rememoradas } \\
\text { por mulheres }{ }^{(17)}\end{array}$ & $\begin{array}{l}\text { Brasil/2016 Rev. } \\
\text { Enferm. UFPE CI- } \\
\text { NHAL Qualitativo }\end{array}$ & $\begin{array}{l}\text { Conhecer a vivência } \\
\text { da amamentação na } \\
\text { adolescência junto a um } \\
\text { grupo de mulheres. }\end{array}$ & $\begin{array}{l}\text { A amamentação foi vista } \\
\text { como algo benéfico passado } \\
\text { de geração para geração, } \\
\text { configurando-se assim como } \\
\text { uma prática cultural, onde } \\
\text { as experiências e o apoio } \\
\text { familiar são decisivos para o } \\
\text { sucesso na amamentação. }\end{array}$ & $\begin{array}{c}\text { Foram incluídas apenas mu- } \\
\text { Iheres que possuíam vínculo } \\
\text { com o serviço de saúde e de } \\
\text { idades diversas. }\end{array}$ \\
\hline $\begin{array}{l}\text { Breastfeeding and com- } \\
\text { plications that contribute } \\
\text { to early weaning }\end{array}$ & $\begin{array}{l}\text { Brasil/2015 Rev } \\
\text { Gaúcha Enferm. } \\
\text { CINHAL Quali- } \\
\text { tativo }\end{array}$ & $\begin{array}{l}\text { Conhecer a vivência das } \\
\text { mães sobre a ama- } \\
\text { mentação e eventos } \\
\text { que contribuem para o } \\
\text { desmame precoce. }\end{array}$ & $\begin{array}{l}\text { As avós maternas não } \\
\text { favorecem a manutenção } \\
\text { do aleitamento materno, } \\
\text { pois possuem uma herança } \\
\text { cultural baseada em conhe- } \\
\text { cimento empírico contrário a } \\
\text { essa prática. }\end{array}$ & $\begin{array}{l}\text { Inclusão apenas de mães que } \\
\text { cadastradas no serviço de } \\
\text { saúde e que tivera parto no } \\
\text { hospital de referência. }\end{array}$ \\
\hline $\begin{array}{l}\text { Aleitamento materno } \\
\text { exclusivo: causas da inter- } \\
\text { rupção na percepção de } \\
\text { mães adolescentes }{ }^{(19)}\end{array}$ & $\begin{array}{l}\text { Brasil/2016 Rev. } \\
\text { Enferm. UFPE CI- } \\
\text { NHAL Qualitativo }\end{array}$ & $\begin{array}{l}\text { Conhecer a percepção } \\
\text { das mães adolescentes } \\
\text { quanto às causas que } \\
\text { influenciam na inter- } \\
\text { rupção do aleitamento } \\
\text { materno exclusivo. }\end{array}$ & $\begin{array}{l}\text { As características pessoais, } \\
\text { crenças, valores e cultura e a } \\
\text { ideia de leite insuficiente para } \\
\text { satisfazer as necessidades } \\
\text { da criança foram os principais } \\
\text { empecilhos para a instituição } \\
\text { do aleitamento. }\end{array}$ & $\begin{array}{c}\text { Inclusão de apenas três bair- } \\
\text { ros da cidade, limitando a um } \\
\text { contexto social da população. } \\
\text { Não foram inseridas ado- } \\
\text { lescentes multíparas, nem } \\
\text { aquelas que tiveram crianças } \\
\text { pré-termo. }\end{array}$ \\
\hline $\begin{array}{c}\text { Sentimentos e vivências } \\
\text { maternas associadas ao } \\
\text { processo de amamen- } \\
\text { tação(20) }\end{array}$ & $\begin{array}{l}\text { Brasil/2015 } \\
\text { CINHAL Rev. } \\
\text { Enferm. UFPE } \\
\text { Qualitativo }\end{array}$ & $\begin{array}{l}\text { Conhecer os senti- } \\
\text { mentos e as vivências } \\
\text { maternas associadas ao } \\
\text { processo de amamen- } \\
\text { tação. }\end{array}$ & $\begin{array}{c}\text { A predominância de senti- } \\
\text { mentos positivos associados } \\
\text { a amamentação, evidenciam } \\
\text { que é um processo histórico, } \\
\text { social, cultural e psicologica- } \\
\text { mente delineado, permeado } \\
\text { por mitos, crenças, tabus e } \\
\text { valores enraizados e cultural- } \\
\text { mente aceitos. }\end{array}$ & $\begin{array}{l}\text { O número de gestantes parti- } \\
\text { cipantes do estudo e inclusão } \\
\text { apenas de mulheres que } \\
\text { tinham filhos acompanhados } \\
\text { pelo serviço. }\end{array}$ \\
\hline $\begin{array}{l}\text { Exclusive breastfeeding: } \\
\text { obstacles presented by } \\
\text { primiparous Women }^{(21)}\end{array}$ & $\begin{array}{l}\text { Brasil/2018 } \\
\text { CINHAL Rev. } \\
\text { Enferm. UFPE } \\
\text { Quantitativo }\end{array}$ & $\begin{array}{l}\text { Identificar os empeci- } \\
\text { Ihos segundo as pri- } \\
\text { míparas das Unidades } \\
\text { Básicas de Saúde, em } \\
\text { relação à amamentação } \\
\text { exclusiva dos filhos nos } \\
\text { primeiros } 6 \text { meses de } \\
\text { vida. }\end{array}$ & $\begin{array}{l}\text { Os mitos e crenças culturais } \\
\text { passadas entre gerações se } \\
\text { constituíram como barreiras } \\
\text { importantes para a institui- } \\
\text { ção da amamentação, princi- } \\
\text { palmente, em primíparas. }\end{array}$ & $\begin{array}{l}\text { Desenho transversal do } \\
\text { estudo e amostra reduzida. }\end{array}$ \\
\hline
\end{tabular}




\begin{tabular}{|c|c|c|c|c|}
\hline $\begin{array}{c}\text { Aleitamento materno: } \\
\text { fatores que influenciam o } \\
\text { desmame precoce entre } \\
\text { mães adolescentes (22) }\end{array}$ & $\begin{array}{c}\text { Brasil/2016 } \\
\text { CINHAL Rev. } \\
\text { Enferm. UFPE } \\
\text { Qualitativo }\end{array}$ & $\begin{array}{c}\text { Os principais fatores são } \\
\text { Identificar os fatores } \\
\text { que influenciam o } \\
\text { desmame precoce em } \\
\text { mães adolescente. } \\
\text { anfluência de pessoas do } \\
\text { contexto social com as quais } \\
\text { essas mães se relacionam, a } \\
\text { introdução precoce de outros } \\
\text { alimentos, a crença/cultura } \\
\text { no mito do leite fraco ou } \\
\text { insuficiente para alimentar } \\
\text { o bebê. }\end{array}$ & $\begin{array}{c}\text { Desenho transversal do } \\
\text { estudo e amostra reduzida. }\end{array}$ \\
\hline Fonte: Elaboração própria. & & \\
\hline
\end{tabular}

um papel crucial nessa tomada de decisão, pois podem influenciar negativamente por acreditarem que o leite materno não é suficiente para suprir as necessidades nutricionais dos bebês. ${ }^{(3,8,10-11,13,15,17-18,21-22)}$

Pode-se verificar também que a existência de uma rede de apoio na amamentação se mostra decisiva para o sucesso na mesma, em culturas onde os companheiros e familiares não acreditam nos benefícios da amamentação pode-se experimentar índices maiores de desmame, demostrando assim a importância da promoção do conhecimento sobre esse hábito em todos os agentes evolvidos nesse processo. ${ }^{(9-11,20)}$

Foi possível notar também que existem diferenças entre a importância e o estímulo ao aleitamento materno dependendo do país, sendo que no Brasil, culturalmente, essa prática é mais estimulada e aceita, diferentemente do que acontece na França e Austrália onde as práticas culturais não estimulam as mulheres a amamentar por considerarem um ato vergonhoso. Podendo entender assim o poder que o imprimting cultural tem na sociedade, principalmente, na instituição do aleitamento materno. ${ }^{(10,14,16)}$

Analisando os artigos pode-se perceber que para as mulheres, a infância é o período motivacional ideal por excelência para integrar a amamentação como a melhor opção para alimentar seus filhos. $\mathrm{Na}$ idade adulta, a motivação transcendente e se consolida no primeiro estágio da educação dos filhos, proporcionando uma maior qualidade motivacional ao prolongamento do aleitamento materno, revelando assim que ao estimular a mensagem da promoção do aleitamento materno na infância maiores serão as chances de perpetuação desse hábito na vida adulta, podendo dessa forma haver melhores índices de sucesso na amamentação e redução do desmame precoce. ${ }^{(11)}$

Cabendo ressaltar ainda a importância dos profissionais e serviços de saúde na promoção do aleitamento materno, pois desempenham o papel de desmistificar e esclarecer conceitos errôneos instituídos culturalmente sobre a amamentação agindo como personagens cruciais no estimulo dessa prática através, principalmente, do aconselhamento subsidiado pela educação em saúde. ${ }^{(8,11-12,19-20,22)}$

\section{DISCUSSÃO}

No tocante as recomendações acerca do aleitamento materno, os órgãos de saúde ao redor do mundo costumam seguir as recomendações da Organização Mundial de Saúde (OMS), que preconiza a amamentação de forma exclusiva até o sexto mês de vida, sendo complementado por dois anos ou mais, garantindo assim todo aporte nutricional e os benefícios que este alimento confere. ${ }^{(23)}$

No entanto, ainda é perceptível que o processo de promoção da amamentação acaba sendo conduzido sob o ponto de vista instintivo e biológico, sem ponderar o grau de complexidade do mesmo, que demanda um olhar criterioso e afetivo sobre a puérpera, bem como um entendimento acerca do contexto cultural em que a díade está envolta, haja vista que os mitos e crenças que perpassam este universo é denso e tendem a apresentar variações a depender das regiões, onde na maioria das vezes são motivadas pelos "achismos", que podem refletir negativamente no tempo de duração da amamentação. ${ }^{(24-25)}$
Envolto deste pensamento, o impriting cultural tem sido apontado como uma das causas que vem contribuindo para que aconteça o desmame precoce, uma vez que as experiências pregressas da família em relação a amamentação, acabam sendo repassadas de geração em geração, o que transmite confiança, sendo estes hábitos em sua maior parte envoltos de aspectos negativos, que costumam serem aceitos pelas puérperas como verdades absolutas, e muitas vezes acabam sobressaindo ao conhecimento científico. ${ }^{(26)}$

Estas constatações estão em consonância com a maioria dos trabalhos aqui selecionados, onde evidenciaram que os hábitos culturais, crenças e tabus de cada localidade, repassados ao longo das gerações, acabam por incidir no poder de decisão para iniciar a prática do aleitamento, bem como na continuação e no ato de cessar. ${ }^{(8,13,15,17-22)}$

Desta maneira, as diferentes regiões elencadas neste trabalho demonstraram uma diversidade de hábitos culturais que refletem diretamente na prática da amamentação, sendo que há uma variação das crenças e tabus, motivados pelas diferenças do impriting cultural entre os diferentes países, onde na estas práticas culturais tendem a reverberar para que haja um desmame precoce.

Um dos hábitos culturais mais citado nos estudos como dificultador do desmame, diz respeito a referência ao "leite fraco" ou "leite insuficiente", onde muitas vezes este pensamento está envolto da interpretação do choro da criança, visto como sinal de fome e necessidade de complementação antes do período recomendado, sendo este pensamento reforçado pela rede de apoio da puérpera. ${ }^{(3,15,19,22)}$ 


\section{artigo}

Vale pontuar que por muito tempo, o hábito cultural do "leite fraco/insuficiente" veio se consolidando e sendo transmitido ao longo das gerações, sem o respaldo científico de veracidade desta informação. No entanto, sabe-se que o leite materno dispõe de todos os nutrientes que a criança necessita até o sexto mês de vida, passando a agir de forma complementar a partir de então. Desta forma, se a criança encontra-se em aleitamento materno exclusivo, quanto mais ela mama, mais leite será produzido visando garantir seu aporte energético. Ademais, a ida mais vezes ao seio materno não caracteriza leite insuficiente, mas que o processo de digestão acontece com maior facilidade frente as fórmulas infantis, sendo que estas informações quando não bem conduzidas tendem a gerar conflitos e findar com a interrupção da amamentação. $(25,27)$

Um outro dado muito pertinente em relação a maneira como o impriting cultural incide nas diferentes regiões, deve-se ao fato do atual cenário político-econômico que tem gerado guerras e condições financeiras desfavoráveis em diversos países, que culminam com a migração dos povos para regiões diferentes da sua cultura. Este fato, acaba tendo reflexos na amamentação, em que a mudança de país já traz arraigado um impacto cultural dificultador e se o novo ambiente não adotar políticas públicas de estímulo a esta prática, estas condutas acabam adquirindo um poder de decisão muito forte em interromper o aleitamento e privar a criança dos benefícios advindos do mesmo, além de que esta mudança gera um distanciamento de uma rede de apoio favorável. ${ }^{(14,16)}$

Esta rede de apoio é imprescindível nesta fase, sendo necessário que as ações de educação em saúde voltadas a promoção da amamentação englobe-as, afim de que a prática do aleitamento seja melhor estimulada e pautada em conhecimentos científicos, sem deixar de ponderar os aspectos culturais e experiências que elas carregam consigo, de modo a ressignificar o que não se encontra em consonância para o bem-estar do binômio mãe-filho, como apontado em um dos estudos em que a falta de apoio do cônjuge para amamentar teve interferência na decisão. ${ }^{(9,25,28)}$

Porém, por mais que a rede de apoio seja importante, não se pode deixar de lado a figura central deste processo, a mãe, e esta dispõe do poder de decisão na condução desta situação, cabendo aos demais integrantes agir de forma positiva para estimular esta prática. Por isto, se faz necessário trabalhar sob o espectro da autoeficácia materna, que é cientificamente comprovado que quanto mais elevada ela se encontrar, maiores são as chances do aleitamento ser iniciado e perpetuado, competindo aos profissionais de saúde atuarem justamente nos pontos de maior fragilidade, ponderando a individualidade de cada mãe, desta forma o enfoque tende a ser mais efetivo, com a prevenção do desmame. (24)

Ademais, se faz necessário também por partes das equipes de saúde um fortalecimento dos vínculos tanto da rede de saúde (atenção básica, hospitais e maternidades), como com os familiares e comunidade, de modo que a promoção da amamentação acontece de forma harmônica e empática, ponderando todo o arcabouço cultural envolto desta puérpera e disseminando informações que atendam as expectativas e necessidades do momento, possibilitando sua implementação, haja vista que é na in- fância que tendem a ser moldados os hábitos culturais que irão perpetuar para a vida adulta. ${ }^{(24,26-27)}$

Uma das limitações elencadas nesta revisão diz respeito a diversidade de metodologias sem uma padronização das mesmas, o que impossibilita conclusões mais fidedignas, haja vista que os vieses de pesquisa foram uma recorrente elencada nos trabalhos selecionados. No entanto, a presença tanto de estudos de natureza qualitativa quanto quantitativa, englobando vários continentes demonstraram que os hábitos culturais influenciam a cultura do aleitamento materno, quer seja ele negativamente ou positivamente.

\section{CONCLUSÃO}

A literatura selecionada apontou para a importância em se ponderar o impriting cultural nas ações de promoção e orientação para o aleitamento materno, tendo em vista que os hábitos culturais vêm arraigados ao longo das gerações, e estes são colocados em prática na maioria das vezes pela rede de apoio das puérperas, tendo um poder de persuasão muito forte. Desta forma, o fortalecimento dos vínculos, bem como um conhecimento mais aprofundado da cultura local permite que as intervenções aconteçam de forma mais satisfatória, contribuindo deste modo para redução do desmame precoce e que as crianças possam usufruir de todos os seus benefícios, haja vista que a amamentação tem repercussões importantes ao longo de toda a vida do ser humano.

Além disso, foi perceptível a necessidade de mais estudos acerca do tema com a utilização de metodologias mais delineadas e padronizadas, que possibilitem uma extrapolação dos resultados mais fidedigna. -

\section{REFERÊNCIAS}

1. Morin E. Introdução ao pensamento complexo. $4^{\circ}$ edição. Porto Alegre (RS): Editora Sulina; 2005.

2. Morin E. O método 4: as ideias habitat, vida, costumes, organização. Porto Alegre (RS): Editora Sulina; 1998.

3. Gonah L, Mutambara J. Determinants of Weaning Practices Among
Mothers of Infants Aged Below 12 Months in Masvingo, Zimbabwe. Ann Glob Health. [Internet]. 2016; 82(5):875-884. doi: http://dx.doi. org/10.1016/j.aogh.2016.10.006

4. Sanches MTC, Carvalho MR, Tavareas LAM. Amamentação com enfoque fonoaudiológico e amamentação com bases cientificas para 


\section{REFERÊNCIAS}

a prática profissional. Guanabara Koogan: Rio de Janeiro; 2011.

5. Vargas JC, Antunes HS. Determinismos culturais frente à ludicidade na infância: conceitos e concepções paradigmáticas. Ver Refelxão e Ação. [Internet]. 2010; 18(2): 136-150. doi: http://dx.doi. org/10.17058/rea.v18i2.591

6. Mendes KDS, Silveira RCCP, Galvão CM. Revisão integrativa: método e pesquisa para a incorporação de evidências na saúde e na enfermagem. Texto Contexto Enferm. [Internet]. 2008;17(4):758-64. doi: http://dx.doi.org/10.1590/S0104-07072008000400018

7. Souza MT, Silva MD, Carvalho R. Revisão integrativa: o que é e como fazer. Einstein. [Internet]. 2010; 8:103-106. doi: http://dx.doi. org/10.1590/s1679-45082010rw1134

8. García-Magdaleno VG, Laureano-Eugenio J. Representaciones sociales frente a la lactancia materna en mujeres rurales y urbanas de jalisco, méxico: estudio cualitativo. Revista Colombiana de Obstetricia y Ginecología. [Internet]. 2019; 70(2): 83-93. doi: https://doi. org/10.18597/rcog.3303

9. Mensah KA, Acheampong A, Anokye FO, Okyere P, Appiah-Brempong A, Adjei RO. Factors influencing the practice of exclusive breastfeeding among nursing mothers in a peri-urban district of Ghana. BMC Res Notes. [Internet]. 2017; 10(466):1-7. doi: 10.1186/ s13104-017-2774-7

10. Pastorelli PPL, Oliveira ECN, Silva LJ, Silva LR, Silva MDB. Significados e experiências culturais em amamentação entre mulheres de dois países. Rev enferm UERJ. [Internet]. 2019; 27:1-7. doi: http://dx. doi.org/10.12957/reuerj.2019.40605

11. Martínez-Poblete G, Ossa X. Motivações para o prolongamento da amamentação. Acta Paul Enferm. [Internet]. 2020; 33:1-8. doi: http://dx.doi.org/10.37689/actaape/2020A00112

12. Tekaly G, Kassa M, Belete T, Tasew H, Mariye T, Teshale T. Pre-lacteal feeding practice and associated factors among mothers having children less than two years of age in Aksum town, Tigray, Ethiopia, 2017: a cross-sectional Study. BMC Pediatrics. [Internet]. 2018; 18(310):1-10. doi: https://doi.org/10.1186/s12887-018-1284-7

13. Tsanidou E, Gougoula V, Tselebonis A, Kontogiorgis C, Constantinidis TC, Nena E. Socio-demographic factors affecting initiation and duration of breastfeeding in a culturally diverse area of North Eastern Greece. Folia Med (Plovdiv). [Internet]. 2019; 61(4):566-71. doi: 10.3897/folmed.61.e47858

14. Gallegos D, Vicca N, Streiner S. Breastfeeding beliefs and practices of African women living in Brisbane and Perth, Australia. Maternal and Child Nutrition. [Internet]. 2015; 11:727-736. doi: 10.1111/ mcn.12034

15. Frota MA, Lopes MF, Lima KF, Sales COCB, Silva CAB. Interfaces of the discontinuation of breastfeeding. Acta Scientiarum Health Sciences. [Internet]. 2016; 38(1):33-38. doi: 10.4025/actascihealthsci. v38i1.28514

16. Moreira MA, Paiva MS, Ramos MNP, Ribeiro PS, Ramos JSBM. Experiências migratórias e intergeracionais sobre a amamentação no espaço familiar: um estudo de representações sociais. Aquichan. [Internet]. 2018; 18(3): 287-297. doi: 10.5294/aqui.2018.18.3.4
17. Cremonese L, Wilhelm LA, Prates LA, Oliveira G, Barreto CN, Ressel LB. O processo da amamentação na adolescência: vivências rememoradas por mulheres. Rev enferm UFPE on line. [Internet]. 2016; 10(9):3284-92. doi: 10.5205/reuol.9571-83638-1-SM1009201613

18. Oliveira CS, locca FA, Carrijo MLR, Garcia RATM. Breastfeeding and complications that contribute to early weaning. Rev Gaúcha Enferm. [Internet]. 2015; 36(spe):16-23. doi: http://dx.doi.org/10.1590/19831447.2015.esp.56766

19. Oliveira AC, Dias IKR, Figueredo FE, Oliveira JD, Cruz RSBLC, Sampaio KJAJ. Aleitamento materno exclusivo: causas da interrupção na percepção de mães adolescentes. Rev enferm UFPE on line. [Internet]. 2016; 10(4):1256-63. doi: 10.5205/reuol.8464-74011-1SM. 1004201612

20. Silva CMS, Bortoli CFC, Massafera GI, Silverio M, Bisognin P, Prates LA. Sentimentos e vivências maternas associadas ao processo de amamentação. Rev enferm UFPE on line. [Internet]. 2015; 9(8):934351. doi: 10.5205/reuol.6812-75590-1-ED.0908sup201502

21. Silva AM, Santos MCS, Silva SRM, Ferreira FA, Freitas RSC, Santos REA, et al. Exclusive breastfeeding: obstacles presented by primiparous women. J Nurs UFPE online. [Internet]. 2018; 12(12):3205-11. doi: https://doi.org/10.5205/1981-8963v12i12a236599p3205-3211-2018

22. Souza SA, Araújo RT, Teixeira JRB, Mota TN. Aleitamento materno: fatores que influenciam o desmame precoce entre mães adolescentes. Rev enferm UFPE on line. [Internet]. 2016; 10(10):3806-13. doi: 10.5205/reuol.9667-87805-1-ED1010201611

23. Ministério da Saúde (BR). Secretaria de Atenção à Saúde. Departamento de Atenção Básica. Saúde da criança: aleitamento materno e alimentação complementar. Za ed. Brasilia: Ministério da Saúde; 2015.

24. Monteiro JCS, Guimarães CMS, Melo LCO, Bonelli MCP. Breastfeeding self-efficacy in adult women and its relationship with exclusive maternal breastfeeding. Rev. Latino-Am. Enfermagem. [Internet]. 2020; 28(3364):1-9. doi: http://dx.doi.org/10.1590/15188345.3652 .3364

25. Marques ES, Cotta RMM, Priore SE. Mitos e crenças sobre 0 aleitamento materno. Ciência \& Saúde Coletiva. [Internet]. 2011; 16(5):2461-2468. doi: http://dx.doi.org/10.1590/S141381232011000500015

26. Sartori CC, Reticena KO, Manfio A, Santos MS, Bravo DS, Valverde VRLV, et al. As crenças que influenciam o autocuidado da puérpera. Brazilian Journal of Surgery and Clinical Research. [Internet]. 2020; 32(1):67-71. Disponivel em: https://www.mastereditora.com.br/periodico/20200907_163646.pdf

27. Zago MG, Maciel CLZ. Conhecimento acerca da amamentação de puérperas internadas em um hospotal particular de Cascavel - PR. FAG Journal of Health. [Internet]. 2020; 2(3): 364-369. doi: https:/doi. org/10.35984/fjh.v2i3.226

28. Junges ACF, Zandoná D, Bervian J. Avaliação de Atitudes e conhecimentos sobre amamentação de mães no puerpério imediato. Rev Pesq Saúde. [Internet]. 2019; 20(2): 67-70. Disponivel em: http:// www.periodicoseletronicos.ufma.br/index.php/revistahuufma/article/view/8065/7870 